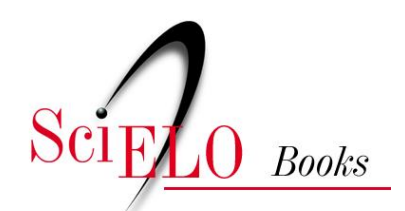

\title{
Análisis de la producción fotográfica y obras audiovisuales de misiones salesianas en la región amazónica
}

\author{
Ángel Torres-Toukoumidis \\ Angélica Almeida-Guerrero
}

\section{SciELO Books / SciELO Livros / SciELO Libros}

TORRES-TOUKOUMIDIS, A., and ALMEIDA-GUERRERO, A. Análisis de la producción fotográfica y obras audiovisuales de misiones salesianas en la región amazónica. In: JUNCOSA BLASCO, J., and GARZÓN VERA, B., eds. Misiones, pueblos indígenas y la conformación de la Región Amazónica: actores, tensiones y debates actuales [online]. Quito: Editorial Abya-Yala, 2019, pp. 165-179. ISBN: 978-9978-10-494-1. https://doi.org/10.7476/9789978104941.0010.

\section{International license.}

Todo o conteúdo deste trabalho, exceto quando houver ressalva, é publicado sob a licença Creative Commons Atribição 4.0.

Todo el contenido de esta obra, excepto donde se indique lo contrario, está bajo licencia de la licencia $\underline{\text { Creative }}$ Commons Reconocimento 4.0. 


\title{
Análisis de la producción fotográfica y obras audiovisuales de misiones salesianas en la región amazónica
}

\author{
Ángel Torres-Toukoumidis ${ }^{1}$ \\ atorrest@ups.edu.ec \\ Angélica Almeida-Guerrero ${ }^{2}$ \\ aalmeida@salesianos.org.ec
}

\section{Introducción}

Este artículo se pregunta cuál ha sido la finalidad de los registros fotográficos y audiovisuales del proyecto educativo-evangelizador de los misioneros salesianos en el suroriente ecuatoriano, específicamente en Morona Santiago, territorio que ha sido ocupado por los pueblos shuar y achuar.

1 Doctor en el programa de Doctorado Interuniversitario en Comunicación bajo la línea de investigación "Educomunicación y Media Literacy" (2014), de las universidades de Huelva, Sevilla, Málaga y Cádiz. Revisor Científico de Comunicar, Revista Científica de Educación y Comunicación.

2 Bibliotecaria y Archivista. 5to semestre de Pedagogía en la Universidad Politécnica Salesiana de Quito. 
El Vicariato Apostólico de Méndez y Gualaquiza, fue confiado a los salesianos el 8 de febrero de 1893 y la primera expedición a Gualaquiza la hicieron en octubre del mismo año, el P. Francisco Spinelli y el hermano Jacinto Pancheri. Su viaje de exploración duró treinta seis días desde Cuenca. En una carta dirigida a Don Rúa, sucesor de Don Bosco, Pancheri expresa lo siguiente:

[...] Me es grato anunciar a V.R. que con el P. Spinelli hemos hecho la primera excursión a Gualaquiza, donde fuimos recibidos con entusiasmo, no sólo de los pocos cristianos que allí hay, sino también de los salvajes Jívaros. (Carta escrita por Jacinto Pancheri a Don Rúa, 20 de noviembre de 1893)

El Boletín Salesiano italiano, una publicación mensual, fundada por el mismo Don Bosco en Turín, por primera vez anuncia la llegada de los misioneros a la Amazonía Ecuatoriana. En julio de 1894, en la sección Noticias de nuestras misiones, Pancheri escribe sobre su viaje exploratorio y se puede observar la primera fotografía del lugar, tres "jívaros" con sus temibles lanzas y su indumentaria étnica, junto a las dos expediciones de salesianos. En el pie de foto consta: "Tres jívaros de Gualaquiza que acompañaron a Cuenca a los Misioneros Salesianos”.

En el mismo boletín, en agosto de 1894, por segunda ocasión se publica una ilustración con el pie de foto: "El tipo Jívaro", junto al relato: "primera conversación con los Jívaros", posiblemente su nombre era Naranza, un jíbaro esbelto y robusto a quien le dedica toda una página.

Desde ese entonces, emerge a la luz la figura física del Shuar, en medio de su cómodo hábitat y nace el interés de la prensa por publicar imágenes de las obras en las misiones amazónicas del Ecuador. De igual modo, Bottasso (1993) resume las caracterizaciones del pueblo shuar realizando una compilación etnográfica sobre su modus vivendi, enfatizando el medio ambiente, los trabajos, el idioma, las pinturas faciales, entre otras.

Posteriormente, cuando llega el vendaval de la Revolución Alfarista que ordenó la expulsión de los salesianos en Qui- 
to, Riobamba y Cuenca. Don Rúa escribió a la casa de Cuenca:

"Ustedes no tengan miedo, vayan a Gualaquiza".

Los misioneros continuaron con su proyecto pastoral-educativo en una situación muy precaria por falta de apoyo del Gobierno. Sin embargo, logran construir dos internados para niños y niñas.

Y comienza a ingresar más personal a la obra. Algunos de ellos dejaron un vestigio fotográfico de la misión y los internos. Más tarde los salesianos que más se dedicaron a la fotografía fueron: Jacinto Pancheri, Fabián Bonato y el Padre José Chierzi, aún en la impresión de la época, positivo a la gelatina-bromuro de plata a finales del siglo XIX y comienzo del siglo XX, llegaron a llamar la atención sobre la presencia de los misioneros y principalmente de la opinión pública, no con la perspectiva de documentar aspectos culturales del pueblo Shuar, sino con dos finalidades que se fueron acrecentando con los años: conseguir vocaciones salesianas y buscar apoyo económico (Batallas, 2017).

Los Shuar aún en 1896, estaban muy seguros de sí y firmes en su cultura como para abrir las puertas de sus comunidades a nuevas formas de vida totalmente distintas, como lo eran los internados. Su estilo de vida, vestimenta, costumbres, hasta su geografía era totalmente desconocida por el propio gobierno. La labor misionera era muy sacrificada y totalmente desconocida por la opinión pública ecuatoriana. Los gobiernos, que poco a poco se volvieron menos hostiles que en los de comienzos de la Revolución Liberal, con reticencia toleraban la presencia de una organización religiosa en la Región Amazónica, pero, su apoyo era casi nulo. Sin embargo, necesitaban de una entidad que integrara a la nacionalidad a un sector al que ninguna de sus delegaciones gubernamentales tenía acceso. Así se cruzan dos finalidades, el gobierno con el afán de civilizar y crear una frontera viva y el de la congregación por evangelizar (Guerriero \& Creamer, 1997).

Los salesianos comprendieron que era indispensable empeñarse para que el Gobierno valorara los servicios en una zona 
aún muy olvidada por las autoridades, y también por la propia nación. De hecho, Bottasso (2006, p. 58) reitera la importancia de la plurinacionalidad de estos buenos pueblos abandonados "Uno puede ser al mismo tiempo, shuar, ecuatoriano y latinoamericano. Lo uno no excluye lo otro", facilitando el empoderamiento y la conjunción identitaria de los pueblos étnicos.

Bajo esta tesitura, la producción fotográfica y audiovisual que produjeron no solo los salesianos, sino también expediciones de los pueblos junto al Amazonas, ayudó para que la prensa escrita respaldara el trabajo de los misioneros y la visibilidad de los pueblos de la Amazonía.

Cuando se menciona producción fotográfica y audiovisual, es menester mencionar al referente, Siervo de Dios, P. Carlos Crespi, realiza el primer film etnográfico sobre los Shuar en 1926. Las tomas originales de apenas 17 minutos, describen sus costumbres diarias, como la caza, pesca y sus fiestas en medio de los avatares de su hábitat selvático, sin sonido y con una de las primeras cámaras que llegan al país. Crespi tituló su filmación: Los invencibles Shuaras del alto Amazonas. Su guion original fue escrito en español e inglés y, puso como encabezamiento esta indicación: "Primer documento cinematográfico originalísimo de la tribu más misteriosa de las selvas americanas Jíbaros o Shuara, debido a la iniciativa de los misioneros salesianos". ${ }^{3}$

Según Pagnotta (2017), esta película que promocionó el proyecto misionero salesiano en la selva ecuatoriana no solo hizo su lanzamiento en el país, sino también fue proyectada en New York y Europa.

El objetivo era lograr el reconocimiento de la opinión pública y principalmente la obtención de recursos para las mismas misiones. Ecuador era un país con una economía reducida y las misiones no resentían de esta situación. Era preciso lograr encontrar a benefactores que ayudaran al trabajo en el Vicariato.

Lo mismo que con la película, con las fotografías que se seguían tomando en medio de la ya consolidada misión: postales, 
imágenes a blanco y negro y más tarde en color. La gran mayoría

no tenían el afán de hacer una demostración etnográfica. Algunas de ellas son reconstrucciones de la vida shuar, exagerando un poco las características etnográficas, en otras se ilustra la labor de la misión selva amazónica. En algunas se representan aspectos menos positivos de los indígenas, hasta un poco denigrantes, para suscitar con ello compasión y sobre todo cooperación para la obra de Don Bosco, lo cual el día de hoy es inaceptable.

El panorama es diferente cuando las relaciones Iglesia-Estado cambian notablemente, cuando en 1937 firman el "Modus Vivendi" con la Santa Sede.

En ese ambiente sereno, el P. Juan Vigna junto al P. Elias Brito, trabajan para lograr que el Vicariato tuviera Personería Jurídica, y esto permite que el conjunto de misioneros pueda presentarse ante el país como una entidad legítima, respetable y de interés nacional.

La guerra del 41, también llamó fuertemente la atención del país sobre el Oriente, puesto que las misiones constituyeron la única presencia capaz de evidenciar la ocupación del territorio de manera continuada y organizada. La educación de los Shuar, casi por completo estuvo sobre los hombros del Vicario. Se pensó entonces en la fórmula de la educación fisco misional, para compartir la responsabilidad entre las misiones y el gobierno.

Alrededor de los años 50 nacen nuevas misiones cerca del Upano y su proyecto educativo crece notablemente. Ya con 11 misiones en el Vicariato el P. Juan Shutka junto al P. Krovina, arman la Radio Federación, a través de la cual se organizan las Escuelas Radiofónicas. Además, buscan difundir la labor de aquellas casas salesianas y dirigen la segunda producción audiovisual de los salesianos. En 1963 filman la película Pescadores del mar verde, un film muy poco conocido, de 41 minutos, que recrea la vida de los Shuar en los internados y describe sus costumbres y ritos. El guion escrito por Shutka, la describe como "película documental de la labor misionera realizada por los misioneros salesianos entre los jíbaros del Ecuador”, fue grabada en las misiones de: Sucúa, Seipa, Kuchantza, Méndez, Chi- 
guaza, Sevilla, Taisha, Paute, Yaupi, Macas, Sucúa y Bomboiza y tuvo como actores a más de 16 Shuar entre hombres y mujeres (Vásquez et al., 2012).

Desde los años 60 hasta la actualidad se han producido miles de imágenes y han formado parte de un fondo fotográfico muy valioso. Actualmente reposan en el Archivo Histórico Salesiano y retratan la realidad de una zona amazónica olvidada, así también como los proyectos llevados a cabo por los misioneros. Hay 15 producciones audiovisuales hasta el año 2007.

El material documentado ha tenido varias interpretaciones y cada imagen seguramente cuenta una historia. Esto nos permite ser testigos de la vida amazónica pasada y conocer las repercusiones que tiene en el presente y futuro.

\section{Metodología}

Esta investigación se fundamenta en la aplicación de una metodología cuanti-cualitativa, en la que se presenta como objetivo general realizar una revisión de producciones del fondo fotográfico y audiovisual de las misiones salesianas en la región amazónica del Ecuador entre 1888 hasta 2007 ordenado en base a dos objetivos específicos, el primero busca organizar el contenido audiovisual producido por las misiones salesianas según el período histórico. Mientras que el segundo objetivo específico pretende determinar la finalidad de dichas producciones audiovisuales realizadas por los salesianos en la selva amazónica destacando el afán de entremezclar los aspectos educativos, culturales e institucionales.

La técnica de recopilación de datos utilizada en esta investigación fue la documentación. Según Sampieri, Collado y Lucio (2010) se trata de una técnica no intrusiva, con alto nivel de autenticidad que utiliza cartas, diarios personales, fotografías, archivos y grabaciones de audio. En este caso, el material recopilado pertenece al Archivo Inspectorial Salesiano proveniente del Vicariato Apostólico de Méndez y Gualaquiza, archivo histórico de Quito, Audiovisuales Don Bosco (ADB), 
obteniendo una muestra de 8870 fotografías reducidas a 7726

dado que se incluyen exclusivamente aquellas realizadas entre 1888-2007 y realizadas sobre las misiones de Méndez, Santiago, Gualaquiza, Macas, Sucúa, Aguacate, Indanza, Limón, Yaupi, Taisha, Bomboiza, Chiguaza, Cuchanza, Wasakentsa y Sevilla y quince documentales, sintetizado en doce omitiendo el género de noticieros, comerciales, pruebas, spots, programas de TV, conciertos y reportajes.

En definitiva, la revisión exhaustiva de las fotografías y documentales se ejecutó durante cinco meses en Quito y Cuenca, buscando obtener la fecha exacta de realización de las fotografías y lanzamiento de los documentales, para ello se contó con el apoyo del personal de Audiovisuales Don Bosco (ADB) y del Archivo Histórico Inspectorial Salesiano, quienes facilitaron la información requerida para la organización según periodo histórico de las producciones.

\section{Resultados}

Primeramente, cabe destacar que gran parte del fondo fotográfico salesiano ha sido recogido del Vicariato Apostólico de Méndez y Gualaquiza, el cual fue confiado a los salesianos el 8 de febrero de 1893. Sin embargo, las primeras evidencias fotográficas nacen en inicios del siglo XX, es muy difícil determinar quiénes han sido los autores, pero se cree que pudo haberlas tomado el hermano salesiano Fabián Bonato y otras probablemente son del Padre José Chierzi. Siendo las primeras fotografías en positivo a la gelatina-bromuro de plata.

La serie del Vicariato Apostólico de Méndez, es muy valiosa porque logra retratar la realidad del Oriente en esa época, que era desconocida, incluso para el propio gobierno.

Los salesianos con el afán de dar a conocer y generar mayor interés en la opinión pública, retratan rostros, las mismas misiones, gran parte de la convivencia, costumbres, vestimenta, de un pueblo escondido, los Shuar, además de la labor pastoral-misionera que emprendieron desde finales del siglo XIX. El afán 
de ellos por documentar y mostrar esa realidad, permitió formar unos de los fondos fotográficos más valiosos del siglo XX.

Los Shuar aún en 1896, estaban muy seguros de sí y firmes en su cultura como para abrir las puertas de sus comunidades a nuevas formas de vida totalmente distintas, como lo son los internados. Se puede decir que hubo un cambio cultural profundo.

Muchas de las fotografías tomadas por los misioneros salesianos, no fueron con el afán de hacer una demostración etnográfica, algunas de ellas son reconstrucciones usando al Shuar como principal protagonista y a la misión como el ambiente en la Selva Amazónica.

En tanto, organizar el contenido audiovisual producido por las misiones salesianas según el período histórico se consultaron los parámetros de la fototeca de la Sociedad Salesiana encuadrando en cuatro etapas pretermitiendo indicadores de cada período como presencia salesiana en el Ecuador, acontecimientos sobresalientes, autoridades salesianas, familia salesiana, obras y pasajes:

- Primer Período (1888-1932): Fundación y Principio de las Obras. 605 fotografías $(8 \%)$ y un documental $(8 \%)$.

- Segundo Período (1933-1958): Consolidación de las Obras. 3136 fotografías $(41 \%)$ sin documentales $(0 \%)$.

- Tercer Período (1959-1988): Expansión de las Obras. 2663 fotografías $(34 \%)$ y 5 documentales $(42 \%)$.

- Cuarto Período (1989-2007): Obras Actuales. 1322 fotografías (17\%) y 6 documentales $(50 \%)$.

En total se revisaron 7726 fotografías, a partir de las cuales se evidencia que el segundo período contiene la mayor cantidad de fotografías, de allí se puede inferir que existe un interés específico por promover y difundir las obras salesianas en el Oriente ecuatoriano, de hecho, de acuerdo con Rubenstein (2005) las continuas relaciones comerciales que venían dándose entre los Shuar y los Macabeos favorecieron en gran medida a la consolidación de las misiones salesianas, consiguiendo en los misioneros un rol intermediario para conseguir mercancías acompañado del 
aprendizaje de las nuevas herramientas y conocimientos proce-

dente de los salesianos. Mientras que, al revisar las producciones audiovisuales, el cuarto período (1989-2007) denominado Obras Actuales se ubican el $50 \%$ de los documentales, esto pudiera implicar que el desarrollo progresivo de las nuevas tecnologías, incorporando softwares de edición de video, cámaras con mayor portabilidad y la aprehensión de conocimientos técnicos ha facilitado la grabación y producción de documentales.

En cuanto al segundo objetivo específico, enfocado en determinar la finalidad de las producciones audiovisuales realizadas por los salesianos en la selva amazónica, los doce documentales revisados desde 1888 hasta 2007 fueron organizados en informativos y promocionales, este último se subdivide en cultural, institucional y educativo.

Tabla 1. Documentales de misiones salesianas en la Amazonía ecuatoriana (1888-2007)

\begin{tabular}{|l|l|l|}
\hline $\mathbf{N}^{\mathbf{2}}$ & \multicolumn{1}{|c|}{ Nombre del documental } & Finalidad \\
\hline 1. & $\begin{array}{l}\text { Salesianos en el Oriente (1960). 22 minutos. Ins- } \\
\text { pectoría Salesiana. Casas salesianas en el oriente, } \\
\text { Macas, Sevilla de Don Bosco, hermanas salesianas, } \\
\text { paisajes y actividades variadas. }\end{array}$ & Informativo \\
\hline 2. & $\begin{array}{l}\text { Orientes y Colorados (1960). 38 minutos. Inspectoría } \\
\text { Salesiana. Tsa'chilas en actividades cotidianas, con un } \\
\text { sacerdote, imágenes aéreas de montañas, casas sa- } \\
\text { lesianas el oriente, aterrizaje de avionetas Servicio } \\
\text { Aéreo misional, bailes de shuara; Tsa'chilas y herma- } \\
\text { nas evangelizadoras. }\end{array}$ & Cultural \\
\hline 3. & $\begin{array}{l}\text { Misioneros con alas (1986). 16 minutos y 30 segun- } \\
\text { dos. Audiovisuales Don Bosco. El Servicio Aéreo } \\
\text { Misional SAM, es un servicio no comercial para las } \\
\text { comunidades del oriente ecuatoriano que facilita el } \\
\text { transporte de las comunidades shuar y achuar ade- } \\
\text { más de ser un aporte a la acción misionera salesiana. }\end{array}$ & Institucional \\
\hline 4. & $\begin{array}{l}\text { El trabajo educativo en Morona Santiago (1987). 15 } \\
\text { minutos. Audiovisuales Don Bosco. Salesianos y sa- } \\
\text { lesianas han educado en el Oriente desde finales de } \\
\text { 1800, con escuelas misionales, talleres de corte, con- } \\
\text { fección, carpintería y mecánica, escuelas agrícolas y } \\
\text { colegios e institutos superiores. }\end{array}$ & Educativo \\
\hline
\end{tabular}




\begin{tabular}{|c|c|c|c|}
\hline 174 & $\mathrm{~N}^{\circ}$ & Nombre del documental & Finalidad \\
\hline & 5. & $\begin{array}{l}\text { Presencia salesiana en el Oriente Ecuatoriano } \\
\text { (1987). } 12 \text { minutos. Audiovisuales Don Bosco. Un re- } \\
\text { corrido por la historia de los salesianos y salesianas } \\
\text { en el Oriente Ecuatoriano, su labor misionera, educa- } \\
\text { tiva y de organización social de los shuaras. }\end{array}$ & Institucional \\
\hline & 6. & $\begin{array}{l}\text { Los Invencibles shuaras del alto amazonas (1995) } \\
\text { [1927]. } 18 \text { minutos y } 30 \text { segundos. Cinemateca Na- } \\
\text { cional, UNESCO y Audiovisuales Don Bosco. Re- } \\
\text { creación de la película del P. Carlos Crespi, en el que } \\
\text { se visualiza escenas de la vida diaria de las comuni- } \\
\text { dades indígenas del Este ecuatoriano. }\end{array}$ & Cultural \\
\hline & 7. & $\begin{array}{l}\text { P. Kreamer. (1997). } 12 \text { minutos. Audiovisuales Don } \\
\text { Bosco. Un recorrido por el trabajo y la historia de los } \\
\text { salesianos en el Ecuador. }\end{array}$ & Informativo \\
\hline & 8. & $\begin{array}{l}\text { Misiones en el Oriente-salesianos en el Ecuador } \\
\text { (1999). } 24 \text { minutos y } 41 \text { segundos. Vicariato de Mén- } \\
\text { dez. El trabajo pastoral del vicariato apostólico de } \\
\text { Méndez, llevado por Monseñor Pedro Gabrielli. }\end{array}$ & Informativo \\
\hline & 9. & $\begin{array}{l}\text { Trabajo educativo en Morona Santiago ( } 2000) \text {. } 23 \text { mi- } \\
\text { nutos y } 40 \text { segundos. Vicariato de Morona Santiago. } \\
\text { Congregaciones y grupos comprometidos con el pro- } \\
\text { ceso educativo en Morona, una metodología pastoral } \\
\text { adecuada. }\end{array}$ & Educativo \\
\hline 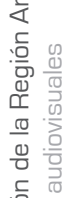 & 10. & $\begin{array}{l}\text { 1er Encuentro Binacional Achuar Ecuador-Perú } \\
\text { (2000). } 15 \text { minutos y } 30 \text { segundos. Fundación Chan- } \\
\text { cuap. Encuentro binacional entre los pueblos shuar } \\
\text { de Ecuador y Perú como consecuencia de la paz fir- } \\
\text { mada por los dos países. Convenios bilaterales. }\end{array}$ & Institucional \\
\hline 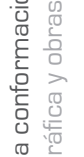 & 11. & $\begin{array}{l}\text { Retratos misioneros (2006). } 26 \text { minutos. Vicariato } \\
\text { Apostólico de Méndez. Un viaje por la vida y servicio } \\
\text { de los misioneros salesianos y de otras comunidades } \\
\text { que trabajan en el Vicariato Apostólico de Méndez. }\end{array}$ & Institucional \\
\hline 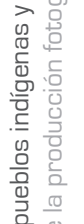 & 12. & $\begin{array}{l}\text { Amanecer de Iglesia Achuar (2007). } 38 \text { minutos. Mi- } \\
\text { sión salesiana de Wasakentza. Visión de la cultura } \\
\text { Achuar, su proceso de desarrollo, sus cambios, su } \\
\text { cosmovisión, desde una perspectiva de la misión sa- } \\
\text { lesiana de Wasakentza y ordenación de un diácono } \\
\text { Achuar. }\end{array}$ & Cultural \\
\hline
\end{tabular}

Fuente: Audiovisuales Don Bosco 
En el 100\% documentales analizados, $25 \%$ son informativos: Salesianos en el Oriente (1960); P. Kreamer. (1997); Misiones en el Oriente-salesianos en el Ecuador (1999), 75\% promocionales, dividido en $33 \%$ institucional: Misioneros con alas (1986); Presencia salesiana en el Oriente Ecuatoriano (1987); Retratos misioneros (2006). 1er Encuentro Binacional Achuar Ecuador-Perú (2000), 25\% cultural Orientes y Colorados (1960); Los Invencibles shuaras del alto amazonas (1995) [1927]; Amanecer de Iglesia Achuar (2007), y 17\% educativo: El trabajo educativo en Morona Santiago (1987); Trabajo educativo en Morona Santiago (2000).

En ese tenor, al particularizar el análisis se evidencian diez cortometrajes y dos mediometrajes - Amanecer de Iglesia Achuar (2007) y Orientes y Colorados (1960)—superando los 30 minutos máximos de un cortometraje, ambos coinciden que también tienen una finalidad cultural, arguyendo que la visibilidad de los aspectos culturales se refleja con mayor contundencia en documentales con mayor duración.

Por su parte, al detallar las categorías de los documentales, aquellos denominados informativos que representan $1 / 4$ de los documentales realizados, se apoya en un discurso objetivo orientado a la exploración de la realidad aduciendo el uso de datos, entrevistas recientes, convirtiéndolo en un suceso noticioso que en ocasiones puede ser dramatizado. Respecto a los documentales promocionales que en este caso contiene $3 / 4$ de los documentales realizados por salesianos en la Amazonía Ecuatoriana revela la intención de favorecer la difusión del quehacer salesiano a través de un alto impacto visual que atraiga la atención del espectador incentivando una actitud positiva hacia las labores salesianas, obtener recursos económicos para sustentar las misiones y motivar a los jóvenes a participar en las misiones. Específicamente, las subcategorías sobre las que recae los documentales promocionales son: promocional-institucional, promocional-cultural y promocional-educativo. Los documentales promocionales-institucionales se refieren a un tipo particular de película en la que se expresan con la voz colectiva y a menudo anónima que dio origen al documental, contando con el apoyo financiero y legal y, en la mayoría de los casos, está regulado 
éticamente por la organización que financia el proyecto. Este estilo de estos documentales no es realmente emocionante y no se basa en la dramatización, sino en el uso del poder del contenido para influir en el espectador. Esto puede hacer que el documental sea menos interesante de ver, pero lo que debemos tener en cuenta en el documental institucional es que la institución está impulsada por el deseo de transmitir un mensaje, pero a menudo limitado por un presupuesto estricto.

Los documentales promocionales de tipo cultural buscan transmitir y articular los procesos humanos mediante el diálogo, argumentación lógica de discusión reivindicándose como arquetipo y modelo básico de la comunicación humana bajo un formato expositivo dialógico como arquetipo y modelo básico de la comunicación humana y modelo de documental etnográfico interactivo (Río \& Álvarez, 1999). En el caso de esta investigación, los documentales culturales analizados demuestran que además de contener una mayor duración, también se observa un enfoque homogéneo del contenido realzando el modus vivendi en las comunidades de los Tsa' chilas, Shuar y Achuar, derivando así en un estudio etnográfico sobre los pueblos del Oriente ecuatoriano.

En cambio, los documentales promocionales-educativos responden a la necesidad de establecer directrices en el proceso de enseñanza-aprendizaje dentro de un contexto particular, específicamente, son videos breves y enfocados en las metas de aprendizaje, que busca resaltar ideas o conceptos importantes mediante un estilo conversacional y entusiasta para mejorar el compromiso e interés de los estudiantes. En esta investigación se hace un recorrido de las escuelas misionales, talleres de corte, confección, carpintería y mecánica, escuelas agrícolas y colegios e institutos superiores. Asimismo, se valoran la metodología pastoral aplicada en las congregaciones y grupos comprometidos con el proceso educativo en Morona Santiago.

\section{Discusión, conclusiones y recomendaciones}

Partiendo de los datos presentados y a la luz de las investigaciones, teoría y objetivos presentados en este capítulo, 
se observa que los dos objetivos específicos del estudio obtuvieron resultados contrastables. En primer lugar, se logró ordenar el contenido audiovisual sobre la Amazonía ecuatoriana siguiendo los parámetros de la fototeca de la Sociedad Salesiana y organizando en 4 períodos en la que destaca una disminución significativa $(-50 \%)$ en el número de fotografías entre el tercer período (1959-1988) y cuarto período (1989-2007) coligiendo en el reemplazo de fotografías por la producción material audiovisual, aumentando la cantidad de documentales orientados a promocionar las misiones salesianas buscando generar interés por parte del público y difundir el reconocimiento de su identidad. En el segundo objetivo específico, se pretende determinar la finalidad de dichas producciones audiovisuales realizadas por los salesianos en la selva amazónica destacando el afán de entremezclar los aspectos educativos, culturales e institucionales, en el que se demuestra que la mayoría de las producciones audiovisuales son institucionales seguida de culturales y en menor grado de tipo educativa. En modo de reflexión, reconociendo la importancia de la enseñanza salesiana y de la metodología de Don Bosco, se debe potenciar la producción de documentales donde se refleje la enseñanza pastoral y la enseñanza profesional con estilo salesiano, destacando la visión pedagógica de "Honrados ciudadanos y buenos cristianos".

Dando un paso más sobre las razones que pudieron afectar el registro audiovisual de las expediciones salesianas en el Oriente Ecuatoriano se encuentra el desarrollo progresivo de Audiovisuales Don Bosco, la tecnificación del personal y el acompañamiento de la Inspectoría Salesiana junto a los grupos de investigación de la Universidad Politécnica Salesiana a partir de los cuales se han generado proyectos de empoderamiento de las comunidades del Oriente otorgándole paralelamente una mayor visibilidad a su modo de vida.

Por su parte, a partir de este primer estudio exploratorio sobre fotografías y documentales se recomienda a los próximos investigadores indagar sobre el trabajo audiovisual y fotográfico posterior a 2007 profundizando aún más en la estética de las 
imágenes, intencionalidad, interpretación ideológica, formatos y contextualización. Complementariamente, el mismo estudio puede trasladarse a otros países que compartan la Amazonía, finalizando con una comparativa entre las expediciones regionales abarcando igualmente los musicales, docu-ficción, spots, video reportajes e independientes.

\section{Bibliografía}

Batallas, C. O. (2017). Las "Exposiciones Orientalistas Salesianas" de 1943-1944: la puesta en escena de la construcción del Estado en la Amazonía ecuatoriana. Procesos. Revista ecuatoriana de bistoria, (45), 65-93.

Bottasso, J. (Ed.) (1993). Los salesianos y la Amazonía. Quito: Editorial Abya-Yala.

(2006). Minorías y democracia en el Ecuador. Quito: Editorial Abya-Yala.

Guerriero, A., \& Creamer, P. (1997). Un siglo de presencia salesiana en el Ecuador: 1888-1898. Quito: s/e.

Il bollettino salesiano (1894). Noticias de nuestras misiones. Roma: Casa Generalicia.

Pagnotta, C. (2017). 'Evangelizar' y 'civilizar' la Amazonía ecuatoriana. Una aproximación a la actividad del salesiano Carlo Crespi en la década de 1920. Reinvención de América Latina. Proyecciones y percepciones Europa-América Latina, siglos XIX-XX.

Río, P. del, \& Álvarez, A. (1999). La puesta en escena de la realidad cultural. Una aproximación histórico cultural al problema de la etnografía audiovisual. Revista de Antropología Social, (8), 121-136.

Rubenstein, S. (2005). La conversión de los shuar. Quito: Flacso.

Sampieri, R., Fernández Collado, C., \& Lucio, P. (2010). Metodología de la investigación. México, DF: McGraw-Hill.

Vásquez, L., Regalado, J. F., Garzón Vera, B., Torres Dávila, V. H., Juncosa Blasco, J. E., Farfán, M., ... \& Llanos Erazo, D. (2012). La Presencia Salesiana en Ecuador: Perspectivas históricas y sociales. Quito: Abya-Yala. 
- Los salesianos comprendieron que era indispensable empeñarse para que el gobierno valorara los servicios en una zona aún muy olvidada por las autoridades, y también por la propia nación.

- Las primeras evidencias fotográficas nacen en inicios del siglo XX, es muy difícil determinar quiénes han sido los autores, pero se cree que pudo haberlas tomado el hermano salesiano Fabián Bonato y otras probablemente son del Padre José Chierzi.

- El material documentado ha tenido varias interpretaciones y cada imagen seguramente cuenta una historia. Esto nos permite ser testigos de la vida amazónica pasada y conocer las repercusiones que tiene en el presente y futuro.

- Los documentales promocionales que en este caso contiene $3 / 4 \mathrm{de}$ los documentales realizados por salesianos en la Amazonía Ecuatoriana revela la intención de favorecer la difusión del quehacer salesiano a través de un alto impacto visual que atraiga la atención del espectador incentivando una actitud positiva hacia las labores salesianas, obtener recursos económicos para sustentar las misiones y motivar a los jóvenes a participar en las misiones.

- Los documentales culturales analizados demuestran que además de contener una mayor duración, también se observa un enfoque homogéneo del contenido realzando el modus vivendi en las comunidades de los Tsa'chilas, Shuar y Achuar, derivando así en un estudio etnográfico sobre los pueblos del Oriente ecuatoriano. 